\title{
Guidelines for Foreign Language Lesson Planning
}

\author{
Benjamin Rifkin \\ University of Wisconsin-Madison
}

\begin{abstract}
In 1982, Knop provided beginning teaching assistants with a "recipe" for planning foreign language lessons; James revisited this effort in 1992. In this article, lesson planning is examined again in light of recent years' research and discussion of foreign language learning and teaching. The background discussion aims to give beginning teachers a sense of the recent history of the teaching of foreign languages in North America and the theoretical foundation of the communicative approach to foreign language teaching. The article also provides practical guidelines for the design of daily lesson plans that integrate culturally contextualized accuracy and fluency activities (for a broad range of skills and in a range of modes) with strategy-based instruction for the communicative curriculum.
\end{abstract}

\section{Introduction}

In 1982, Knop published a groundbreaking article that offered beginning teaching assistants a "recipe" for planning foreign language lessons. This effort was undertaken again by James in 1992. Indeed, it seems that the profession requires renewal of this basic task about every 10 years. This article provides beginning teachers and teaching assistants with background on the recent history of foreign language teaching in North America and the theoretical foundation of the communicative approach. It also offers a practical guide to planning foreign language lessons in elementary, secondary, and postsecondary contexts.

\section{Historical Background}

Foreign language educators today might look back on the period before 1980 with a certain sense of nostalgia. Before that time, it seemed as if educators knew with certainty what it was they had to do in the foreign language classroom. Before 1950, it seemed clear that the purpose of learning a foreign language was two-fold: (1) for learners to become acquainted with the literary canons of Ancient Greece and Rome, among others, and (2) for learners to train their minds by diagramming sentences and studying the grammar and syntax of these classical languages. The foreign language curriculum was dominated by an approach now called "the grammar-translation method," in which students translated into and out of the target language and there was little, if any, communicative use of the target language in the curriculum.

In the middle of the $20^{\text {th }}$ century, foreign language educators became more interested in spoken (modern) languages and in their students' ability to use them to communicate. B. F. Skinner's understanding of stimulus-response conditioning created a framework for the approach to foreign language teaching that came to be called "the audiolingual method." At that time, it seemed as though the profession had found the truth: Language learning was a behavioral task. Instructors only had to provide the correct stimulus in order to elicit the correct response. Students memorized and recited dialogues by the hundreds.

It seemed to many that methodology had been perfected with the advent of audiolingualism. In his landmark 1967 study, "Foreign Language Proficiency Levels Attained by Language Majors near Graduation from College," Carroll demonstrated, however, that American college students majoring in foreign languages completed their studies with competencies significantly lower than expected (Carroll, 1967). Clearly, the audiolingual method was not attaining the

Benjamin Rifkin (PhD, University of Michigan) is Professor of Slavic Languages at the University of Wisconsin-Madison, Madison, Wisconsin. 
results it was supposed to achieve: Students came home from study abroad experiences complaining, "the French don't know the same dialogues we know!" As Swaffar explained, in response to Carroll's revelations, American foreign language educators came to redefine second language learning as "the ability to perceive and operate within real-world situations, in order to perform real-world tasks" (1989, p. 55).

The position of grammar in the grammar-translation and audiolingual methods was central. Grammar remains to this day an important topic in the foreign language curriculum, but it cannot be the most important. If foreign language teachers teach only grammar, students will never learn to communicate; however, they will not be able to communicate without learning some grammar. The difficult questions of today that foreign language educators must answer for themselves and their students include how much and what grammar to teach, and how to teach it, within the context of a communicative foreign language curriculum.

Foreign language educators must also consider research in education more broadly, as well as research in second language acquisition - the discipline that studies how individuals and societies acquire (and lose) second or foreign languages. (An individual studies a "second language" in the culture in which that language is spoken, such as the study of English as a Second Language (ESL) in the United States, whereas an individual studies a "foreign language" in any culture in which that language is not spoken, such as the study of Japanese in the United States.) The following is a synopsis of some of the most important developments in research in education and in second language acquisition that are relevant to foreign language educators. (This research informs the lesson planning guidelines that will follow.)

One of the most important $20^{\text {th }}$ century discoveries about learning (not just in the area of foreign language learning) is Ausubel's (1968) concept of "meaningful learning." Ausubel's "meaningful learning tasks," as distinguished from "rote learning tasks," are those that require the learner's active mental participation in relating new information to existing knowledge. The audiolingual approach to foreign language learning - that model of rote language instruction that emphasizes stimulus-response drills - lacked meaningful learning tasks and content.

There seems to be a consensus among researchers in second language acquisition theory regarding the importance of extended, authentic, comprehensible input (VanPatten, 1992a; 1992b). Researchers and practitioners with views as different as Krashen (1982) and McLaughlin (1987) cited authentic, comprehensible input as one of the most important pieces of the foreign language acquisition puzzle, and placed the development of receptive skills as a prerequisite for the subsequent development of productive skills.
McLaughlin and others associated with the "Information Processing Theory" of second language acquisition emphasized in their writings the importance of helping learners to structure their learning experience. According to McLaughlin, Rossman, and McLeod (1983), learners impose organization on the language data they receive. More successful students somehow know intuitively how to organize this information to facilitate its retrieval from long-term memory. Other students, perhaps the vast majority, need their teachers' help in organizing the information so they can use it appropriately.

It is plausible that the majority of foreign language teachers themselves come from the group of more successful students and thus know intuitively how to organize information in the foreign language learning process. However, successful foreign language teachers must be able to work not only with students who also have this intuition, but with those who do not. Instructors can help the latter by teaching them language learning and processing strategies. Many researchers argue that strategy training helps students improve their reading comprehension and problem-solving skills (O'Malley \& Uhl Chamot, 1990). Language learning strategies might include tactics for learning new vocabulary (e.g., by means of visual imagery or better time management). Language processing strategies might focus on roots, prefixes, and suffixes to decode an unknown word, or involve watching a videotape without sound to observe visual cues that help the learner identify the main idea of the text before attempting to extract even more information when hearing it.

Wagner-Gough and Hatch (1975), associated with what may be called the "Discourse Theory" of second language acquisition, argued that success in instructed foreign language acquisition depends on the degree to which learners are provided opportunities to engage in actual foreign language discourse. In other words, students need to use language structures and vocabulary in a meaningful way, rather than merely listen to and repeat them on the appropriate audiolingual cues. The importance of discourse opportunities, according to Wagner-Gough and Hatch, in some ways corresponds to the notion of "skill-using" activities as described by Rivers (1969). The discourse theory of second language acquisition certainly makes intuitive sense: It would be impossible to imagine learning how to drive a car without actually having an opportunity to get behind the wheel of a vehicle and drive it.

Lastly, many writers have singled out the reduction of social distance from native speakers of the target language as one of the most important steps in the foreign language learning process. According to the "Acculturation Theory" of second language acquisition, in order for learners to succeed with their efforts, they must become comfortable interacting with native speakers. This means that they must 
study not only the target language, but also the associated culture. Without studying the target culture, students will not be able to speak the language appropriately and to understand the behavioral and sociolinguistic norms of the target culture (e.g., see Byrnes, 1991, p. 208). Analysis of the target culture and comparison to the base culture, an important criterion set forth in the national standards for foreign language learning (discussed later), should be a point of departure for the design of language learning activities, because it helps learners understand their own assumptions and biases with respect to both cultures.

\section{Communicative Language Teaching}

Many college and university foreign language programs are designed to help students achieve certain goals. Typically, these goals include some of the following:

- Listening comprehension (and, in some cases, viewing comprehension)

- Reading comprehension

- Speaking ability

- Writing ability

- Understanding the culture(s) in which the language is spoken

- Understanding the perspectives of different cultures

Of course, foreign language programs may have other goals, too, such as understanding the history or literary traditions of the people who speak the given language. These goals have both long-term and short-term consequences for curriculum. In the long-term, the course each instructor teaches must fit into the larger language instruction sequence, from the first day of class to, at the least, completion of the foreign language requirement (but preferably to commencement day). Sometimes the sequence of study includes study abroad or short-term trips or exchanges to the target culture; in some cases, students might host a student or students visiting from the target culture. In the short-term, teachers must meet their supervisors' and students' expectations with regard to how semester- or yearlong courses help move students towards the achievement of the long-term goals.

In the long term, instructors must focus on the program's, institution's, or school board's goals and vision for students' foreign language achievements. In this context, instructors should try to document students' success using foreign language skills after completion of the learning sequence (e.g., by archiving letters and e-mail messages from former students, in which they write about their experiences abroad, placement into college foreign language programs, or successful employment using their foreign language skills).

Communicative language programs have certain characteristics, some of which have been observed by Swaffar,
Arens, and Byrnes (1991). These researchers cited providing students with opportunities to use the language to express personalized meanings and to listen, view, and read authentic texts, while requiring students to study grammar outside of class so that communicative activities could be emphasized during in-class time, as typical teaching strategies.

Many foreign language teachers at all levels of instruction believe that the ACTFL (American Council on the Teaching of Foreign Languages) Proficiency Guidelines provide a good framework for the organization of the foreign language curriculum. The term "proficiency" in the foreign language field is a construct that refers to the degree (how well) an individual communicates (performs) in a given language. The foreign language field has come to recognize the ACTFL Proficiency Guidelines as a scale, a series of descriptors identifying degrees of success in communication in each of the four skills: listening, reading, writing, and (especially) speaking.

The descriptors for speaking - the "Oral Proficiency Guidelines" - provide us with a means of assessing how well an individual speaks a given language. That assessment is related to underlying competencies, including grammatical, sociolinguistic, discourse, and strategic competencies. In the context of the oral proficiency interview, assessment of proficiency is related to the student's execution of language functions (ability to complete tasks), ability to organize words into structures (phrases, sentences, paragraphs, multiple paragraphs), use of speaking contexts (formal/informal, predictable/routine, etc.), and accuracy in speaking. "Accuracy" here refers to grammatical, syntactical, and sociolinguistic accuracies.

Thus, oral proficiency can be considered a construct of communicative performance. The field's focus on oral proficiency is likely a consequence of the fact that the modality of speaking is the only one of the four modalities to have found its reflection in an internationally recognized test (the oral proficiency interview). Tests of proficiency in listening, reading, and writing do exist in some of the more commonly taught languages, but do not have the same widespread acceptance. It is hoped that the coming years will see the development of tests in the other skill areas for a broad range of languages.

Many postsecondary foreign language curricula are constructed around the goal of student proficiency; that is, instructors teach students to become proficient users of the language, to be able to communicate in the target language. In this regard, it is useful to consider Omaggio-Hadley's (2000) five hypotheses about (principles of) proficiencyoriented instruction. According to Omaggio-Hadley, teachers in the communicative foreign language classroom need to devote significant amounts of attention to both the development of students' receptive skills (listening and reading) and productive skills. ${ }^{1}$ With regard to the produc- 
tive skills of speaking and writing, Omaggio-Hadley emphasized that teachers have to provide instruction that balances the development of students' speaking (or writing) fluency and the development of accuracy (broadly defined to include not only grammar, but also syntax, pronunciation and intonation, lexicon, etc.). However, an exclusive devotion to accuracy-focused activities may have the unintended effect of driving some students away from language studies, and may ultimately undermine the selfconfidence they need to develop fluency (see, e.g., Oxford, 1999, and de Andres, 1999). If, on the other hand, a curriculum offers too many fluency-focused activities, students may fail to develop an understanding of the grammar and syntax of the target language. The lack of mastery of grammar and syntax may ultimately hinder them, especially as they aspire to reach higher levels of proficiency.

Thus, foreign language teachers should strive for a balance of accuracy-and fluency-focused activities. The precise nature of that balance will probably vary from language to language according to the design of the language programs in which they teach. It will also vary from day to day, as instructors take on different topics that make greater or lesser demands on students' grammatical and cultural competencies.

The proficiency guidelines provide foreign language instructors with a framework of functions or task hierarchies that can be used to construct a curriculum, leading learners from task to task as they improve their skills at using the target language to communicate. The Standards for Foreign Language Learning in the 21st Century (National Standards, 1999) provide teachers with direction as to what the content of courses might be. As Sandrock (2002) explained, the national standards represented an important shift in the understanding of the learning and teaching dynamic:

The key shift in using standards to guide language programs is moving from an emphasis on teaching to a focus on learning. Standards tell us what the student does, not what the teacher does; the targeted performance for students is described, not what the teacher does to create that performance (p. 5).

The national standards comprise five areas: communication, cultures, connections, comparisons, and communities. Each standard area has goals that are content-oriented (see Appendix A). The standards provide foreign language teachers at all levels of instruction with direction as to the kinds of content they can use to fill their curricula. For example, teachers can design tasks that engage students in such activities as reading about the interests of young people at a target culture Web site (intermediate level listening proficiency/Standards 1.2, 2.1, and 3.2); sharing with each other in the target language their reactions to, and interpretations of, material they have read (intermediate level oral proficiency/Standards 1.1 and 2.1); and asking questions and learning from an émigré from the culture they are studying (intermediate level oral proficiency/Standard 5.1) in order to make cultural and linguistic comparisons (Standards 4.2 and 4.1).

\section{Towards Guidelines for Lesson Planning}

I provide here a theoretical framework for the integration of accuracy and fluency tasks/activities in the communicative foreign language curriculum. The goal of accuracy tasks or activities is the promotion and development of students' accuracy in using the target language, whereas fluency tasks or activities are those that promote and develop fluency in other words, their communicative performance skills. The framework for the integration of these two kinds of activities is based on the following four assumptions derived from McLaughlin's cognitive theory of second language learning (McLaughlin, 1987; McLaughlin et al., 1983):

1. Elementary, secondary, and postsecondary learners of foreign languages may not be able to learn a foreign language in the same way that they learned their native language as infants and toddlers.

2. Learners are limited in how much they can focus their attention and in how much information they can process in any given instant.

3. Some learners may need to process language structures and routines consciously (learning) before they can do so automatically (acquiring), although Krashen would argue that learners may need to go through the process in the reverse sequence.

4. Instruction in learning strategies (including cognitive, metacognitive, and affective) is an effective way to help learners speed up their acquisition process (see O'Malley \& Uhl Chamot, 1990, p. 222)

Despite the fact that virtually all foreign language students at every level of instruction will continue to make structural errors as they communicate in the target language in foreign language classrooms, instructors must provide them with opportunities to practice communication. Without such opportunities, students are doomed to fail in communication with native speakers.

How then can we teach communication? Rivers distinguishes "skill-getting" activities from "skill-using" activities in that the latter are "autonomous" and provide learners with opportunities to express their own meanings, to be creative with language, and to communicate meaningful information in the classroom. Whereas skill-getting activities are focused on accuracy, skill-using activities are focused on fluency. When students engage in skill-using activities, they must attend primarily to meaning, rather than to form. If students are to wait until they master the entire grammar before they engage in any genuine fluency 
activities, most will simply never learn to communicate in the target language. On the other hand, if classes are planned to consist entirely of skill-using activities, students will probably never achieve a reasonable degree of accuracy in their language use and may be unable to move beyond intermediate level proficiency.

The resolution of this dilemma lies in the recognition of two facts long recognized by many in the foreign language profession. First, accuracy is an important goal of foreign language instruction at some levels, but it is not the most important goal at every level of instruction and in every context. Second, teachers must promote the development of students' grammatical competence (accuracy), but not lose sight of the larger goal of proficiency, or communicative performance. Accordingly, foreign language classroom exercises and activities should not lead up to, and end with, grammar exercises. Instead they must culminate in opportunities for learners to use the foreign language for genuine communication.

\section{Fluency Activities}

An examination of foreign language textbooks quickly reveals that, historically, they have provided an abundance of explanations and exercises intended to help improve students' grammatical competence (e.g., Rifkin, 1992; Walz, 1986). There seems to be no lack of materials focusing on grammatical competence. Nonetheless, fluency activities are a critical part of any successful foreign language curriculum and instructors must be ready to design them when textbooks lack a sufficient number of them to achieve a balance of learning activities.

Previous efforts to define the principles underlying the design of fluency activities (for instance, Nunan, 1989; Paulston \& Selekman, 1976; Rivers, 1969), have failed to account for the balance of attention to both accuracy and fluency in the larger lesson plan. Furthermore, these efforts do not systematically account for the explicit instruction of learning strategies, which is so important to the acquisition process. Any attempt to design a model lesson plan for the communicative foreign language classroom must provide for a balance of attention to both accuracy and fluency, and help students to use learning strategies that will accelerate the acquisition process.

Fluency tasks should begin with comprehensible input (listening and/or reading texts): This is of critical importance. Comprehensible input is essential for the foreign language lesson if only because student success is contingent upon exposure to the language: Higgs (1991) calculated that the total time of exposure to the language in a four-year course of instruction at the postsecondary level is equivalent to a mere 70 days in the target culture. As Scarcella and Oxford argued (1992), students are unable to process all of the language material instructors provide; if that includes only minimal comprehensible input, students are unable to take up and process very much of the language. On the other hand, students given an abundance of input have numerous opportunities to take up and process at least some of it.

Fluency tasks should feature culturally authentic and personalized information-gap activities (Nunan, 1989). The concept of the gap reflects the actual goal for communication: we listen and read to extract information and we speak and write to convey information. The information gap may be genuine (students talk about their own life experiences with one another) or contrived (students talk about life experiences from the perspective of an assigned or adopted persona or mask). The information gap should be culturally authentic: Students should not be asked to role play selling papaya at a farmer's market in Oslo in a Norwegian class. Fluency tasks should be personalized: Students should have some degree of personal investment or ownership of the activity. They should be asked to contribute information based on their own personal experiences (genuine information gap) or on the basis of their interpretations of someone else's experiences (contrived gap). In this regard, student choice is a critical factor in the success of fluency activities.

Fluency tasks should also include some strategy instruction, such as the use of circumlocution or approximation in speaking, or the reliance on an understanding of roots and prefixes in interpreting a written text. Strategy instruction is of critical importance for helping all the students in the class, not just those with the intuitive understanding of how to interpret a text or give a presentation in the target language. Strategy instruction is also essential in building learners' repertoires of approaches to tasks requiring use of the target language within and beyond the curriculum (Standard 5.2).

\section{Table 1}

CHARACTERISTICS OF

SUCCESSFUL FLUENCY ACTIVITIES

1. Comprehensible input

2. Culturally authentic and personalized information gap

a.genuine (students share authentic information)

b.contrived (students share information assigned

to them)

3. Strategy instruction

4. Targeted language functions, text types, modes of language use

5. Accountability phase 
Of course, fluency tasks should be selected to cover a range of language functions (narration, persuasion, and so forth) and modes of language use (interpretive, interpersonal, presentational).

Lastly, fluency tasks should conclude with an accountability phase, in which students demonstrate their mastery of the skills, concepts, or information presented (perhaps with a chart, graph, collage, oral presentation, or written report). The materials produced for this phase of the fluency task can be included in students' learning portfolios as samples of their work in using the language.

For example, half of a class could be given a letter describing a family from Venezuela, focusing on the daily routine of some of the members of the family; the other half could be given a magazine article about standards of living in Venezuela. After working with maps to remember the location of Venezuela and its relevant cities or towns, the students could be assigned to identify learning objectives (what they hope to learn from each text) and some strategies they might use to decode the text or parts of it that they might not understand. Students might work in pairs or groups to extract information from the assigned text and then be assigned to work in different pairs or groups to share that information with students who had read the other text.

Next, students could be asked to compare and synthesize the information from the two different sources, including the identification of elements of different stylistic registers typical of an informal letter and a magazine article. They should also consider the different strategies they have used to understand the assigned texts. Students might then be required to prepare short presentations or reports comparing the information they have learned about family life in Venezuela with family life in their own community or in another Spanish-speaking country, perhaps on the basis of an interview with an émigré.

The lengths of the assigned texts (from a few sentences to a few pages) and presentations (a few minutes or more) would vary with the learning stage of the students, from beginning and developing levels to transitioning and refining levels (Sandrock, 2002). It is of critical importance to select the text and fashion the task in accordance with student preparation for both, as will be explained in the next section.

\section{The Integration of Accuracy and Fluency Activities}

To prepare students to complete the preceding sample task on family life in Venezuela, the teacher may need to provide some instruction about the use of the imperfect tense for expressing repeating or frequent events or actions. This kind of learning experience would naturally come under the rubric of accuracy activities. When faced with tasks for which they lack accuracy preparation, some students become very frustrated, but others avoid frustration at a linguistic cost: They begin to use nonnormative grammar or syntax, which can become difficult, if not impossible, to correct. These students find the means to communicateoften just barely - and then lose any motivation to clean up their language. In the foreign language methodology literature, this phenomenon has been called "fossilization" or, more accurately, the stabilization of learner interlanguage in ways that differ from the norms of the target language (Gass \& Selinker, 2001, p. 12).

Some researchers argue that explicit accuracy instruction is futile or counterproductive (summarized by Ellis, 2002; Fotos, 2002); others argue that there is a place for accuracy instruction in the communicative foreign language curriculum (summarized by Ellis, 2002). In arguing one side or the other, researchers look perhaps too closely at languages close to English (Romance and Germanic languages, which fit this description, are the most commonly taught foreign tongues in the United States), or the teaching of English as a second language. These comparisons provide the context for conclusions that are claimed to be generalizable to other contexts. In fact, in the case of American learners of Russian, much of the data suggests that accuracy instruction is an essential part of the curriculum for those learners seeking the highest levels of proficiency (Brecht, Davidson, \& Ginsberg, 1993). I take the position that accuracy instruction is an integral part of the foreign language curriculum, but that it must take its place together with fluency-focused instruction. Moreover, regardless of which language and at what level it is taught, instructors must consider carefully the balance and sequencing of accuracy and fluency activities.

Some instructors may complain that their students demonstrate "absolutely terrible" control of grammar during fluency activities, and thus they cannot afford to assign any fluency activities. Investigating further, however, it can often be found that the fluency tasks in which these students made innumerable errors were very challenging and likely far above their level of competence. Magnan (1985) has shown that when students are challenged to complete a task that lies far beyond their level of proficiency, they make numerous errors in the use of structures they had previously mastered. For instance, if a Chinese language student with intermediate level oral proficiency and relatively good control of the fundamentals of interpersonal speech at the sentence level in Chinese, is assigned to explain economic trends and market forces in contemporary China, he or she is likely to have a complete linguistic breakdown. This task is more appropriate for a student at a much higher proficiency level. If the same student is assigned to describe what she did over the weekend, she might actually rise to the occasion.

It is essential that students be challenged with com- 
municative tasks that lie slightly above their current proficiency level, in accordance with Swain's theory of pushed output (Swain, 1985); without such challenge, their oral skills are not likely to improve (Magnan, 1985, p. 121, citing Kaplan, 1985, 1986). However, if students are challenged with communicative tasks too far above their current proficiency level, they will likely become frustrated and discouraged as they fail. The first and most important criterion for the design of a lesson is the appropriate match (by level of difficulty) of tasks and the students who will complete them.

The second criterion for the creation of the lesson plan is this: Accuracy and fluency activities must be carefully designed and sequenced within the lesson plan. Lesson plans and activities must be structured in a way that will systematically help students gain the skills they need to communicate independently in the target language. In the guidelines that follow are points that researchers in second language acquisition have identified as critical for successful foreign language instruction: meaningful learning tasks, authentic comprehensible input, opportunities for meaningful and communicative discourse in the target language, and familiarization with the target culture.

\section{Lesson Planning Guidelines}

On the basis of the latest research in learning and teaching of foreign languages, the following are guidelines for lesson planning in the proficiency-oriented communicative foreign language classroom at levels $\mathrm{K}-16$. These guidelines (adapted from Knop, 1982, and James, 1992) should be used in a spiral for the integration of accuracy and fluency tasks, taking learners from beginning phases of instruction to later phases, revisiting the same thematic content (e.g., family structure, health and illness, etc.) in different modes, with different language functions and skills.

\section{The Five-Phase Lesson Plan}

(1) The Overview phase (also called "Preview" by James [1992]) should include a brief statement of goals and learning objectives for the learning activity and may be provided in the L1 or L2 in writing and/or in speech.

(2) The Preparation phase (also called "Prime" by Knop [1982]) may include discussion of appropriate learning or language processing strategies, but should always include presentation of listening and reading texts and language processing tasks. The texts should be culturally authentic and promote the development of intercultural understanding. Students should be provided with the cultural information needed to complete tasks and should work to identify appropriate background information, schemata, and cultural references.

(3) The Drill and Practice phase should always include opportunities for discourse and may be based on interpre- tation of listening or reading texts presented in the preparation phase; drill may be more teacher-centered, but practice must be learner-centered. Practice may be spoken or written, and interpersonal or presentational in mode. In oral communication activities, students should work in pairs or groups on a communication task embedded in a cultural context.

(4) In the Check (or accountability) phase, students demonstrate their mastery of the skills and concepts taught in the lesson. This phase may include presentations (oral or written) or the submission of graphs, charts, or other individual or group.

(5) The Follow-up phase includes cultural comparisons and strategy discussion.

\section{Overview}

The overview phase helps students become oriented to the lesson and its objectives, thus providing them with an advance organizer that they can use to structure the information they receive in the course of the lesson or activity. This information can be provided in writing, on the blackboard, in the target language or in English.

\section{Preparation}

The preparation phase is the ideal time in the instructional sequence to provide students with authentic and comprehensible target-language input (that can be used later as a model for subsequent production, but not only for this purpose) and tasks that will promote processing the meaning of this input. The preparation phase thus corresponds to two stages of receptive processing in the learning continuum described by Magnan (1985), recognition and memorization, in which learners first come to grips with the language material - stages that must precede those involving active use or production. This is also the opportune time to help learners activate learning and languageprocessing strategies that will help them accomplish the language task ahead; see, for example, O'Malley \& Uhl Chamot (1990); Oxford, Ehrman, and Lavine (1991); Oxford and Nyikos (1989). In fact, learners might be assigned to read How to Be a More Successful Language Learner (Rubin \& Thompson, 1994), a more user-friendly approach to the same issues.

\section{Drill and Practice}

It is in the drill and practice phase that students should be encouraged to produce language and to move toward accurate language production. To do so, they must first devote some energy to assisted language production, characteristic of the controlled processing of language material (as described by McLaughlin et al., 1983). This is, therefore, the phase when instructors can implement the first two steps of the Paulston/Selekman three-step drill plan 
(1976), which provides a blueprint for the design of accuracy tasks that move towards fluency tasks. The first step should consist of mechanical or manipulative exercises (with convergent responses and no truth value). For example, the following script depicts the use of a substitution format and transformation formats of two types. (Samples of exercises on this page are translations of student interactions in a Russian-language class.)

\section{Mechanical/Manipulative Exercises}

(convergent responses with no truth value)

1. Teacher: With whom are they dissatisfied? (He)

2. Class: They are dissatisfied with him.

3. Teacher: With whom are they dissatisfied? (She)

4. Group of students: They are dissatisfied with her.

5. Teacher: With whom are they dissatisfied? (We)

6. Individual student: They are dissatisfied with us.

The next step in the Paulston/Selekman plan is devoted to meaningful activities (that may have convergent responses but also have truth value).

\section{Meaningful Exercises}

(convergent or divergent Responses with truth value)

1. Teacher: With whom is Bush dissatisfied?

2. Group 1: Bush is dissatisfied with the Democrats.

3. Group 2: Bush is dissatisfied with McCain.

4. Group 3: Bush is dissatisfied with the Greens.

5. Group 5: The problem is not who [sic] is Bush dissatisfied, but rather who is dissatisfied with Bush. People in California are very dissatisfied with Bush.

In the second example, the groups of students come up with interesting answers, and the fifth group demonstrated at least conceptual mastery of the targeted syntactical structure by coming up with a clever response. The truth value in this last task helps prepare students for the more autonomous communicative activity that follows in the practice phase.

During the drill phase, it is important to vary student response patterns. Instructors should consider the stress that students feel when speaking in front of their peers in general, let alone in a foreign language. Instructors can use choral responses (whole class), group choral responses, pair responses, and then individual responses to help students feel more comfortable before they answer individually. In dividing students into groups for group choral responses, instructors can use: (1) seating patterns (left side of the room vs. right, front vs. back), (2) clothing (e.g., students wearing jeans vs. all others), (3) gender (females vs. males), and so forth, as long as instructors vary the criterion by which they create the groups. Instructors should use different question types to build student confidence and competence - by giving them easier ones (yes/no, either/or) before asking them to take on harder questions (e.g., a transformation drill with the conjugation of a verb, or something like What's this?).

The term "drill" is, for many of us, associated with the audiolingual type of stimulus/response exercise and has come to mean an exercise that is in its nature "teacher-centered," despite Knop's own description of this phase: "as the [drill phase] activity progresses the teacher says less and less to cue students or model for them. The activity should now move to student-student interaction. . .." (1982, p. 92). The drill phase is a very appropriate and necessary component for the introduction of new language material. It gives learners a chance to try out new lexical, grammatical, or syntactical constructions with appropriate and sensitive feedback from the instructor (or from other learners).

It is useful for teachers to keep drill patterns short, varying only the targeted item of instruction, and providing learners with lots of repetition and positive reinforcement of correct or appropriate utterances. The drill phase can also be called the presentation phase in those situations in which the focus of the learning activity is listening or reading: The teacher presents material that learners must process and provides the information they need to do so.

In all cases, instructors should carefully consider numerous factors before responding to learner errors; errors are a natural part of learner "interlanguage" and a reflection of the students' efforts to approximate the norms of the target language with successive "passes" from year to year in the foreign language curriculum. While some researchers believe in the critical importance of measured feedback to learner errors (e.g., Larsen-Freeman, 1995) and some of them have found certain error correction strategies to be more productive than others (e.g., Lyster \& Ranta, 1997), other scholars believe that error correction is never or rarely beneficial (e.g., VanPatten, 1988).

Factors to consider before responding to a student's error include the nature of the error and the degree to which it impedes communication with a native speaker who knows no English; the degree to which it violates a target culture taboo; its frequency; the degree to which it is part of the focus of the given lesson or unit; how the learner responds to such feedback; and the nature of the class and the impact of the response on the community of learners. Feedback for learners is an important part of the work of all teachers, but error correction can play a large and unproductive role in the creation of a classroom atmosphere in which learners are anxious and stresse and therefore unable to learn as much or as well as might be hoped. (For more information on affect in language learning, see Arnold, 1999).

Foreign language education and second language acquisition researchers know now that the term drill as used 
by adherents of the audiolingual model is not sufficient for the development of autonomous communicative performance; instead, "practice" in the foreign language classroom is required. The most important part of the word "practice" is act: The students must act and interact. Interaction can be achieved in pairs or small groups, using the target language to negotiate meaning. Students may get up out of their seats, talk with partners and others (in a "mingle" activity), or find someone they haven't spoken to yet that day or that week. They can be given charts to fill out on the basis of each interaction, or a task to complete on the basis of another student's answers (e.g., "Find a student who has more than two siblings"). Or, students can be put in groups and then the groups can be shifted so that each is split and reconstituted with some new members. The students can interview one student and then report to another student or work in teams to debate an interesting question.

The combinations and recombinations are infinite. Changing the interaction formats on a daily or weekly basis keeps the interactions fresh, interesting, and exciting for the students. In one such activity - a variation on the game "telephone" - focusing on past tense narration, students could be assigned to tell a partner what they did the preceding weekend (or vacation), or to tell the story of the worst day they had in the past year; that partner would then report this information to a new partner, but in so doing would introduce some distortions and exaggerations. The new partner tells the story again to yet another partner, introducing yet more distortions and exaggerations. The final partner reports back to the class as a whole and the class votes on each item of the narrative, deciding whether it is likely to be true or not. Students get involved in listening and speaking in successive past-tense narrations as they are engaged in the fun of learning about what their classmates do in their free time and enjoying the imagined, and sometimes absurd, changes. A follow-up discussion could focus on which of the free-time activities mentioned might be typical of students the same age in the target culture, why some of the activities would be atypical in the target culture, why others that might be typical for the target culture were not mentioned, and so on.

Practice provides students the opportunity to engage in target language discourse with one another, using the target language to fill information gaps (sharing ideas and opinions with one another.) It is the practice phase in which students move toward autonomous and automatic language processing. Students can use the language structures without thinking about them per se, and talk without additional assistance from the instructor. Compelling the students to verbally exchange information corresponds with what some in the field of second language acquisition are calling "comprehensible output." Swain (1985) wrote:

Comprehensible output ... is a necessary mecha- nism of acquisition independent of the role of comprehensible input. Its role is, at minimum, to provide opportunities for contextualized, meaningful use, to test out hypotheses about the target language, and to move the learner from a purely semantic analysis of the language to a syntactic analysis of it. Comprehensible output is, unfortunately, generally missing in typical classroom settings. ... (p. 252).

Without the practice phase, the foreign language classroom lacks precisely that which teaches students the skills they need to communicate with native speakers. It is precisely for this reason that teachers must emphasize the practice phase of the lesson in the communicative foreign language classroom. Together, the drill and practice phases of the five-phase model correspond to the last two parts of the learning continuum, contextualization and integration, discussed by Magnan (1985), in which learners actively use the language, first in carefully structured discourse and finally in genuinely independent discourse.

\section{Check (Accountability)}

The check or accountability phase provides students opportunities to demonstrate their mastery of the new language material; this phase also provides instructors a means of holding students accountable for completing the task assigned in the time allotted. Students can be expected to report their findings to the whole class, to present skits, or to write a paragraph on the blackboard - all are typical "summary" activities that hold students accountable for the group learning they were assigned. This phase is essential, not for student learning, but for the teaching process, because it provides the teacher with the critical information needed to go on to the next learning event: Have the students mastered the material just presented? Teachers can ask the students, "Did you understand?" but the answer is never as meaningful as evidence the teacher collects in an accountability phase task.

Moreover, this phase is not without consequences for the learning process itself: Knowing that the accountability phase task is coming motivates many students to "get the job done," rather than merely go through the motions. Presenting their findings in front of the entire class is a good motivator for many students. In a large class, it may not be possible to have all students report back to the class, but if they are selected randomly in each accountability phase task, all students will prepare as if they will be called upon.

\section{Follow-Up}

The fifth phase of the integrated lesson plan, the "followup," should provide opportunities for students to discuss among themselves and with their instructor their suc- 
cesses or failures in the assigned task. In this phase, students should work to identify problems or obstacles they had difficulty in overcoming, and the degree to which learning and/or language processing strategies helped them. This is also the opportune time for the instructor to identify common errors committed during the practice and check phases.

Finally, it is in the follow-up phase that students should be required to return to discussion and analysis of larger cultural issues, resuming and synthesizing discussion that was initiated in earlier phases of the lesson. In the course of this response, students and instructor should compare the target and base cultures with respect to the spoken, written, and artistic texts that were presented to students and produced by them in the course of the lesson or in the last few lessons, with an eye toward identifying and explaining the processes, products, and perspectives of the target language culture.

\section{Modular Structure}

The five-phase lesson plan can be spiraled through accuracy and fluency tasks to give learners opportunities to use controlled processing to deal with language material in earlier stages of instruction, and more automatic processing later. In a 50-minute lesson, instructors might present four modules, each mapped out to consist of the five phases described above. For example, a Russian lesson for an upper-level course focusing on the home as a cultural topic might consist of four modules, as outlined in Table 2.

The flow of the modules, or activities, from receptive skills to productive skills, gives students the opportunity to notice lexicon and points of grammar and syntax before having to use them. The implementation of the five-phase lesson plan for each of the modules provides for a carefully designed lesson in which students are well prepared for each task at hand, whether it be listening or reading, and for an easy transition into the next module.

\section{Table 2}

\section{SAMPLE LESSON PLAN}

(0) Homework for the lesson: A short reading about homes and apartments featuring targeted constructions important for this topic (location; possession; verbs of standing, hanging, lying), most of which the students have encountered before this course, and an explanation of the use of these constructions.

(1) Reading activity: Students read a short essay from an illustrated magazine about new trends in home design for the wealthy "new Russians"; students are required to answer questions about content, decode new words related to the topic "home," and notice constructions expressing possession and location. In the follow-up phase of this module, students discuss cultural differences in what constitutes a desirable home for new Russians and what they consider a desirable home for themselves.

(2) Listening/viewing activity: Students watch a short segment from a Russian television program in which a star describes her new home; students are required to answer questions about content, decode new words related to the topic "home," and notice constructions expressing possession and location. In the follow-up phase, students discuss whether the cultural differences they perceived in the reading activity were confirmed or refuted in the listening/viewing activity.

(3) Speaking activity: Students are reminded of expressions for location ("to the right of," "to the left of," etc.) and possession with inanimate subjects (e.g., "the living room has a fireplace") and are drilled in the use of these constructions. They then are assigned to work in pairs. Each partner of the pair is given a home design or plan and describes it (unseen) to his or her partner. The partners then draw the designs based on the verbal descriptions and, ultimately, compare the drawings with the printed plans. Lastly, the partners discuss what aspects of the home plans they personally like and dislike and why, and what aspects of the home plans the Russians featured in the reading and viewing activities might like or dislike and why.

(4) Prewriting activity: Students work in pairs to prepare to write a composition (for homework) on the topic: "My Ideal Home" from their own personal perspective or from the perspective of a famous personality (real or fictitious). In the prewriting activity, they draw up a list of vocabulary items they will need and together write topic sentences for each of the paragraphs of the composition.

(5) Preparation for next days' classes: The topic for next two days will be comparison of homelessness in the United States and Russia and the issue of affordable housing in both cultures. Targeted structures will include comparatives and quantitative expressions. 


\section{Conclusion}

The foreign language lesson should consist of tasks in the sequence described above, to help students move systematically from linguistic dependence on the teacher to greater and greater independence from the teacher. The goal is for learners to use the target language to express their own ideas.

To use the metaphor of teaching someone to swim, teachers must first hold learners up in the water so they don't sink; teach them how to paddle; then how to kick; then how to paddle and kick; then how to turn their heads and breathe; then how to paddle, kick, and turn their heads and breathe. At some point, teachers must take their arms away or the students will never swim on their own. Autonomous function is the ultimate goal of the communicative foreign language classroom. These lesson planning guidelines aim to help instructors understand how to sequence learning tasks appropriately, when and how to provide support for language use in those learning tasks, and when and how to withdraw that support.

\section{Acknowledgments}

I thank anonymous reviewers for their helpful suggestions, but I take responsibility for any errors in this article.

\section{Notes}

1. The term "receptive skills" is used here not to suggest that learners are in any way "passive" when listening or reading texts. Rather, "receptive" is used to indicate that the learners are receiving a listening or reading text in an interpretive or interpersonal mode and reacting to it, by extracting information or aesthetic value, for example. "Productive skills" is a term used to describe the skills of speaking and writing, to convey the idea that students are producing discourse of some kind, in interpersonal or presentational mode.

\section{References}

Arnold, J. (1999). Affect in language learning. Cambridge: Cambridge University Press.

Ausubel, D. (1968). Educational psychology: A cognitive view. New York: Holt, Rinehart, \& Winston.

Brecht, R. D., Davidson, D. E., \& Ginsberg, R. (1993). Predictors of foreign language gain in study abroad. Washington, DC: National Foreign Language Center.

Byrnes, H. (1991). Reflections on the development of crosscultural communicative competence in the foreign language classroom. In B. Freed (Ed.), Foreign language acquisition research and the classroom (pp. 205-218). Lexington, MA: D. C. Heath.
Carroll, J. (1967). Foreign language proficiency levels attained by language majors near graduation from college. Foreign Language Annals, 1, 131-151.

de Andres, V. (1999). Self-esteem in the classroom or the metamorphosis of butterflies. In J. Arnold (Ed.), Affect in language learning (pp. 87-102). Cambridge: Cambridge University Press.

Ellis, R. (2002). The place of grammar instruction in the second/foreign language curriculum. In E. Hinkel \& S. Fotos (Eds.), New perspectives on grammar teaching in second language classrooms (pp. 17-34). Mahwah, NJ: Lawrence Erlbaum $\&$ Associates.

Fotos, S. (2002). Structure-based interactive tasks for the EFL grammar learner. In E. Hinkel \& S. Fotos (Eds.), New perspectives on grammar teaching in second language classrooms (pp. 136-154). Mahwah, NJ: Lawrence Erlbaum \& Associates.

Gass, S. M., \& Selinker, L. (2001). Second language acquisition: An introductory course. Mahwah, NJ: Lawrence Erlbaum \& Associates.

Higgs, T. (1991). Research on the role of grammar and accuracy in classroom-based foreign language acquisition. In B. Freed (Ed.), Foreign language acquisition research and the classroom (pp. 46-53). Lexington, MA: D. C. Heath.

James, C. (1992). What TAs need to know to teach according to the new paradigm. In J. Walz (Ed.), Development and supervision of teaching assistants in foreign languages (pp. 135-152). AAUSC Series Issues in Language Program Direction. Boston: Heinle \& Heinle.

Knop, C. (1982). Overview, prime, drill, check: an approach to guiding student teachers in lesson-planning. Foreign Language Annals, 15, 91-94.

Krashen, S. (1982). Principles and practice in second language acquisition. Oxford: Pergamon.

Larsen-Freeman, D. (1995). On the teaching and learning of grammar: challenging the myths. In F. R. Eckman, D. Highland, P. Lee, J. Milcham, \& R. Rutkowski-Weber (Eds.), Second language acquisition theory and pedagogy (pp. 131-150). Mahwah, NJ: Lawrence Erlbaum \& Associates.

Lyster, R., \& Ranta, L. (1997). Corrective feedback and learner uptake: Negotiation of form in communicative classrooms. Studies in Second Language Acquisition, 19, 37-66.

Magnan, S. S. (1985). From achievement toward proficiency through multi-sequence evaluation. In C. James (Ed.), Foreign language proficiency in the classroom and beyond (pp. 117-145). Lincolnwood, IL: National Textbook Co.

McLaughlin, B. (1987). Theories of second-language learning. London: Edward Arnold.

McLaughlin, B., Rossman, T., \& McLeod, B. (1983). Secondlanguage learning: an information-processing perspective. Language Learning, 33, 135-58.

National Standards in Foreign Language Education Project. (1999). Standards for Foreign Language Learning in the 21st Century. Yonkers, NY: National Standards in Foreign Language Education Project.

Nunan, D. (1989). Designing tasks for the communicative classroom. Cambridge: Cambridge University Press. 
Omaggio-Hadley, A. (2000). Teaching language in context. Boston: Heinle \& Heinle.

O’Malley, M., \& Uhl Chamot, A. (1990). Learning strategies in second language acquisition. Cambridge: Cambridge University Press.

Oxford, R. (1999). Anxiety and the language learner: New insights. In J. Arnold (Ed.), Affect in language learning (pp. 58-67). Cambridge: Cambridge University Press.

Oxford, R., Ehrman, M., \& Lavine, R. Z. (1991). Style wars: teacher-student style conflicts in the language classroom. In S. Magnan (Ed.), Challenges in the 1990s for college foreign language programs (pp. 1-25). Boston: Heinle \& Heinle.

Oxford, R., \& Nyikos, M. (1989). Variables affecting choice of language learning strategies by university students. The Modern Language Journal, 73, 291-300.

Paulston, C., \& Selekman, H. (1976). Interaction activities in the foreign language classroom, or how to grow a tulip-rose. Foreign Language Annals, 9, 248-254.

Rifkin, B. (1992). The communicative orientation of Russianlanguage textbooks. Slavic and East European Journal, 36, 463-488.

Rivers, W. (1969). Speaking in many tongues: Essays in foreign language teaching. Rowley, MA: Newbury House.

Rubin, J., \& Thompson, I. (1994). How to be a more successful language learner $\left(2^{\text {nd }}\right.$ ed). Boston: Heinle \& Heinle.

Sandrock, P. (2002). Planning curriculum for learning world languages. Madison, WI: Wisconsin Department of Public Instruction.
Scarcella, R., \& Oxford, R. (1992). The tapestry of language learning. Boston: Heinle \& Heinle.

Swaffar, J. (1989). Curricular issues and language research: The shifting interaction. ADFL Bulletin, 20(3), 54-60.

Swaffar, J., Arens, K., \& Byrnes, H. (1991). Reading for meaning: An integrated approach to language learning. Englewood Cliffs, NJ: Prentice Hall.

Swain, M. (1985). Communicative competence: Some roles of comprehensible input and comprehensive output in its development. In S. Gass \& C. Madden (Eds.), Input in second language acquisition (pp. 235-253). Rowley, MA: Newbury House.

VanPatten, B. (1988). How juries get hung: Problems with the evidence for the effects of a focus on form. Language Learning, 38, 243-260.

VanPatten, W. (1992a). Second-language-acquisition research and foreign language teaching, Part 1. ADFL Bulletin, 23(2), 52-56.

VanPatten, W. (1992b). Second-language-acquisition research and foreign language teaching, Part 2. ADFL Bulletin, 23(3), 23-27.

Wagner-Gough, J., \& Hatch, E. (1975). The importance of input data in second language acquisition studies. Language Learning, 25, 297-307.

Walz, J. (1986). Is oral proficiency possible with today's French textbooks? Modern Language Journal, 70, 13-20. 


\section{APPENDIX A}

\section{The "Five Cs" of the National Standards for Foreign Language Learning*}

\section{Communication: Communicate in Languages Other Than English}

1.1 Students engage in conversations, provide and obtain information, express feelings and emotions, and exchange opinions. 1.2 Students understand and interpret written and spoken language on a variety of topics.

1.3 Students present information, concepts and ideas to an audience of listeners or readers on a variety of topics.

\section{Cultures: Gain Knowledge and Understanding of Other Cultures}

2.1 Students demonstrate an understanding of the relationship between the practices and perspectives of the culture studied. 2.2 Students demonstrate an understanding of the relationship between the products and perspectives of the cultures studied.

\section{Connections: Connect with Other Disciplines and Acquire Information}

3.1 Students reinforce and further their knowledge of other disciplines through the foreign language.

3.2 Students acquire information and recognize the distinctive viewpoints that are only available through the foreign language and its cultures.

\section{Comparisons: Developing Insight into the Nature of Language and Culture}

4.1 Students demonstrate understanding of the nature of language through comparisons of the language studied and their own. 4.2 Students demonstrate understanding of the concept of culture through comparisons of the cultures studied and their own.

\section{Communities: Participate in Multilingual Communities at Home and Around the World}

5.1 Students use the language both within and beyond the school setting.

5.2 Students show evidence of becoming life-long learners by using the language for personal enjoyment and enrichment.

*From: National Standards in Foreign Language Education Project. (1999). Standards for Foreign Language Learning in the 21st Century. Yonkers, NY: National Standards in Foreign Language Education Project. 